\title{
\#MeToo in regional, rural and remote Australia: An analysis of regional newspapers reports profiling the movement
}

\author{
Rachel Loney-Howes \\ Lecturer in Criminology \\ University of Wollongong \\ AUSTRALIA \\ Bianca Fileborn
Lecturer in Criminology
University of Melbourne
AUSTRALIA
}

Contact author - Rachel Loney-Howes; rlhowes@uow.edu.au

Thanks to the anonymous reviewer for their helpful comments. This research received no funding.

\begin{abstract}
The \#MeToo movement sparked a global conversation and moment of reckoning in relation to sexual violence. The hashtag campaign, developed from a tweet sent by actress Alyssa Milano (though the phrase was originally coined by African American activist Tarana Burke some decade earlier), provided a moment for survivors to share their experiences in a context in which they were perhaps more likely to be supported and believed. The \#MeToo movement also created an opportunity to engage in a more productive dialogue about the causes and the challenges underpinning the prevention of gender-based violence. Yet, \#MeToo has been subject to substantive critique, particularly in relation to modes of representation within media reporting. In addition, there is also little is known about how the \#MeToo movement was impactful beyond major urban centres and resonated in regional, rural, and remote (RRR) locations. This article addresses both these issues drawing on a thematic analysis of 70 newspaper articles from RRR newspapers in Australia reporting on or responding to the \#MeToo movement. While the data reveals some progressive approaches to documenting how the \#MeToo movement impacted some RRR communities, as well as profiling some of the key challenges facing RRR communities in addressing gender-based violence, the specific voices represented in newspaper reporting, continues to reflect the perspectives of white, heterosexual women. We conclude by suggesting further research exploring the nature of reporting on \#MeToo in other RRR spaces is needed to understand the full extent to which sexual violence is understood and represented. In addition, more specific work with survivors in RRR Australia and globally is vital to understand the dynamics and complexities of responding to and preventing sexual violence and the challenges associated with the geographies of speaking out.
\end{abstract}

Keywords: \#MeToo, media reporting, gender-based violence, rural criminology, Australia. 


\section{Introduction}

The \#MeToo hashtag "moment" (Boyle, 2019) emerged on Twitter after US actress Alyssa Milano put out a call to arms to survivors of sexual harassment and violence on Twitter in the wake of allegations against Hollywood mogul Harvey Weinstein. As is now well-recognised, the response to Milano's tweet was phenomenal, with millions of survivors and allies using the hashtag on Facebook and Twitter within the first 24-hours, followed by two years (and continuing) of sustained global conversation and activism in relation to sexual violence (Boyle, 2019; Fileborn \& Loney-Howes, 2019; Gill \& Orgad, 2018). The hashtag movement has been heralded for creating space for survivors to share their experiences in a context of support and belief, and for drawing attention to the 'magnitude' of both 'everyday' and 'extreme' forms of sexual violence, particularly (but not exclusively) in women's lives.

However, \#MeToo has also been subject to sustained and extensive critique, the most prominent of which relates to the initial erasure of African American activist Tarana Burke, who had developed the phrase "Me Too" some decade earlier through her work with young African American women and survivors. Critiques have also been levelled at the campaign on account of its perceived failure to include the experiences of marginalised groups, including people of colour, LGBTIQ+ communities, survivors in the Global South, older women, and many more (Ison, 2019; Kagal et al., 2019; Phipps, 2019; Ryan, 2019). Media reporting on \#MeToo has also faced significant criticism from feminist scholars for the problematic way perpetrators and alleged perpetrators of sexual assault, as well as survivors, were represented (Hindes \& Fileborn, 2019, 2020; Royal, 2019). These news media representations are part of a long history of mainstream media reporting that has sensationalised rape and sexual assault in ways that reinforce problematic stereotypes about real rape and victimisation and offer simplistic analyses of the causes and impacts of sexual violence (Horeck, 2004).

In addition to these extensive critiques, one major absence in the discussion to date has been a consideration of how geography, specifically rurality, has influenced and shaped the ways \#MeToo was made sense of. The \#MeToo Rising website (Google Trends, 2020) which provides a visual representation of Google trends relating to \#MeToo - suggests that engagement with and media reporting on the movement has been predominantly limited to the major urban centres in Australia, such as Melbourne, Sydney, Adelaide, and Perth. Although \#MeToo gained geographic traction beyond the confines of Hollywood and other parts of the English-speaking world - for example, the hashtag was translated into multiple different languages and used to advance more specific local feminist agendas (Garibotti \& Hopp, 2019; Zeng, 2019) - the uptake and response, in general, has been predominantly in urban contexts. This article seeks to fill this gap in knowledge by examining the ways the \#MeToo movement was reported on in news media in regional, rural, and remote (herein RRR) Australia. While some work has begun to examine gender-based violence (GBV) in RRR contexts, feminist criminological and sociological scholarship has typically shared this urban bias. Thus, this article further seeks to contribute to redressing the urban bias in much criminological scholarship (Carrington et al., 2014; Donnermeyer, 2016, 2017; Donnermeyer \& DeKeseredy, 2008).

In order to achieve these aims, we firstly sketch out the literature on media reporting about sexual violence, before situating our work within the extant scholarship on RRR space and place, and RRR GBV. Utilising a thematic analysis of 70 articles from RRR Australian newspapers reporting on \#MeToo, we firstly explore the ways the \#MeToo movement 
impacted these specific locations, and secondly examine how voices are represented when speaking out about GBV in an RRR context. We demonstrate that media reporting on the \#MeToo movement in RRR Australia in many ways challenges the normative historical tropes around the representation of sexual violence and victim-survivors' voices. In addition, media reporting draws attention to some of the specific challenges in addressing sexual harassment and violence in RRR communities. Given the increased homogenisation of the news media industry in Australia coupled with the reduction in local reporters in many regional centres (Dwyer \& Muller 2016; Finkelstein et al., 2012) it is remarkable that such progressive reporting and profiling of the \#MeToo movement has taken place. However, we also note the absence of accounting for Aboriginal women in many RRR parts of Australia, along with members of the LGBTQ+ community. As such, we argue that media reporting on sexual harassment and violence in RRR parts of Australia reflects the enduring erasures of the voices of survivors who are not white, middle-class heterosexual women. Yet, the data presented in this article is by no means representative of all RRR reporting on \#MeToo and sexual violence more broadly. Therefore, we conclude by suggesting that further research exploring the nature of reporting on \#MeToo in other RRR spaces is needed to understand the full extent to which sexual violence is understood and represented. In addition, more specific work with survivors in RRR Australia and globally is vital to understand the dynamics and complexities of responding to and preventing sexual violence and the challenges associated with the geographies of speaking out.

\section{Media reporting on GBV}

There is now a wealth of research on news media representations of GBV. How news media frames GBV can contribute towards public (mis)understandings of this phenomena (Easteal et al., 2019; Harrington, 2018; Morgan \& Simons, 2018; O'Hara, 2012; WaterhouseWatson, 2016; Sutherland et al., 2017), the importance of which should not be understated, given that a large minority of the population adheres to problematic beliefs about GBV (Morgan \& Simons, 2018; Smith et al., 2019). News media can also influence how survivors understand their own experiences. Jenny Kitzinger's (2001) work, for example, demonstrates how media coverage of child sexual abuse can provide survivors with a vocabulary to disclose their experiences to others (see also Palmer-Mehta, 2018). This is not to suggest that news media audiences digest reporting in a simplistic and uncontested way; readers may challenge and disrupt news media discourse, or interpret reporting in vastly different ways (Harrington, 2018). Nonetheless, media reporting is a key site of discourse on GBV and plays a central role in shaping how this issue is articulated and understood, and in driving primary prevention efforts, policy and other responses (Sutherland et al., 2017; Sutherland et al., 2019).

Unfortunately, much research points towards the role of news media in (re)producing myths and stereotypes about GBV in various forms (Easteal et al., 2019; O'Hara, 2012; Royal, 2019; Waterhouse-Watson, 2016). Framing of news stories on GBV can work to subtly or explicitly reproduce notions of the ideal or deserving victim, such as through reference to age, sexual experience, and assessments of whether the survivor acted appropriately (Breen et al., 2017; Easteal et al., 2019; Hindes \& Fileborn, 2019; O'Hara, 2012). Conversely, those who are deemed 'undeserving' victims may be apportioned blame and responsibility, or have their experience discredited (Breen et al., 2017; Easteal et al., 2019; Harrington, 2018; Hindes \& Fileborn, 2019; O'Hara, 2012; Royal, 2019). Media discourse can function to minimise sexual violence as 'just' sex, reinforcing stereotypes of what constitutes real rape (Breen et al., 2017; Harrington, 2018; Hindes \& Fileborn, 2019). 
Following from this, perpetrators in cases constructed as "just sex" tend to be framed as ordinary men, while perpetrators of real rape are positioned as monsters (Hindes \& Fileborn, 2019; O'Hara, 2012). Representations of perpetrators are further constructed through the lens of race, with Rae Pepin's (2016) analysis of US media reporting finding that the behaviour of White male perpetrators of intimate partner violence was more likely to be excused or justified compared to that perpetrated by Black men. Sensationalised, salacious, and pornographic accounts of sexual and other violence are commonly documented (Breen et al., 2017; Easteal et al., 2019; Smith et al., 2019). The tendency to focus on the salacious and sensational points to the centrality of newsworthiness in determining which types of GBV are given media attention. Traditionally, the focus has been on forms of GBV that meet legal thresholds of harm, and that reflect stereotypes of real sexual (and other) violence (Hindes \& Fileborn, 2019; Kitzinger, 2004).

Recent news media analysis has illustrated how reporting can work to centre the perpetrator while silencing survivor's voices. Breen et al.'s (2017) analysis of a high-profile Australian rape trial, for example, found that news media reporting emphasised the negative impact the guilty finding would have on the perpetrator's future prospects and his persistent claim that the encounter was a consensual one (see also Smith et al., 2019). In contrast, the survivor's voice was less commonly quoted, and quotes used from her victim impact statement "served to discursively minimise her experience" (Breen et al., 2017, p.248; see also O'Hara, 2012; Sutherland et al., 2019). In other cases, the actions and responsibility of the perpetrator are obscured through the use of passive voice, with GBV becoming something that just happens to women (Easteal et al., 2019). Recent research analysing Australian media reporting on the \#MeToo movement shows that the bulk of reporting continued to perpetuate the myths and stereotypes outlined here, though there was also evidence of nuanced and progressive reporting (Hindes \& Fileborn, 2019, 2020). Collectively, this body of literature points to the role news media plays in minimising, normalising, and downplaying the nature, extent, and seriousness of GBV (Easteal et al., 2019; Hindes \& Fileborn, 2019). In short, news media forms part of the broader 'rape culture' that enables GBV to occur.

However, it is important to note that these problematic media representations are far from universal. Numerous contemporary studies have documented examples of media reporting that works to contest and disrupt myths and misconceptions about GBV, and present feminist analysis of GBV, even if this is typically in a minority of reporting (e.g., Breen et al., 2017; Easteal et al., 2019; Harrington, 2018; Hindes \& Fileborn, 2019; Morgan \& Simon, 2018; Palmer-Mehta, 2018; Sutherland et al., 2017). As Breen and colleagues (2017, p.255) suggest, this observation is important as "it points to editorial judgements being made about relevance or perceived news value." Thus, news media has the potential "to interrupt and disrupt rape myths and dominant discourses on sexual violence' - the perpetuation of myths and stereotypes should not be viewed as an inevitability (Hindes \& Fileborn, 2019, p.15; see also Morgan \& Simons, 2018).

While the research to date has provided valuable insights into news media representations of GBV - including in relation to the \#MeToo movement - to the best of our knowledge, no research that has specifically considered how Australian RRR media outlets framed the \#MeToo movement. As we move on to illustrate, GBV manifests in specific ways in RRR contexts, suggesting there is a need to undertake a focused analysis of RRR media reporting. 
\#MeToo in regional, rural and remote Australia: An analysis of regional newspapers reports profiling the movement - Loney-Howes and Fileborn

\section{Conceptualising rural/regional space}

Before we examine the specificities of GBV in RRR Australia, it is important to outline what constitutes RRR space, as the meaning of these terms is far from pre-given. On one level, defining RRR locations seems to be a straightforward task. A purely spatial, or points on a map, approach might suggest that RRR spaces can be identified by their relative distance from major urban locations, additionally characterised by small population size and low population density (ABS, 2001; see also Donnermeyer, 2017; Wendt, 2016). While diverse, RRR towns share some common elements, such as small populations:

$[R]$ anging from 80 to a few thousand people. They usually have very limited access to many things taken for granted: large supermarkets, clothing stores, entertainment, mobile phone coverage, public transport, etc. Many of these communities used to have [Indigenous] missions on the edge of town. (Adams \& Hunter, 2007, p. 26)

While many RRR communities may share some of these features, it is simultaneously important not to approach them as homogeneous or stable. Rather, as DeKeseredy and colleagues (2016, p.167) remind us, "there is great variability in the social structure both within and between" urban and RRR places. Further, this seemingly common-sense definition is readily destabilised - as Donnermeyer (2017, p. 120) asks, "what, exactly is meant by small and is there a cut-off point to distinguish what is small and therefore rural from what is large and therefore urban?" Such questions point to the arbitrary and contested production of the 'rural'. Donnermeyer's critique suggests that RRR and urban spaces are not discrete or bounded categories. Rather, the boundaries between and across these spaces are permeable and blurred. Distinctions between RRR and urban are further complicated through their entanglement with digital space and processes of globalisation, both of which work to collapse the virtual and cultural distance between RRR and urban (Donnermeyer, 2017).

Notably, seemingly common-sense approaches miss the importance of RRR place, which cannot be reduced to a simple 'point on a map' (Harris, 2018). Placemaking instead asks that we consider the social and cultural (re)production of a space, a process that is fluid, continually evolving and intertwined with power relations. As Carrington and colleagues (2013, p. 5) explain, rural communities are "not static, ahistorical or placeless", and we must consider "the interaction between sociality and spatiality." The "sociality" of RRR spaces can include particular manifestations of masculinity, ideological beliefs "about resilience and self-reliance" (Carrington et al., 2013, p. 5), privacy, a suspicion of outsiders, and a tendency towards conservative political and social views (Pease, 2010; Ragusa, 2017). In the Australian context, we must also understand RRR spaces as ones marked by the ongoing violence of colonisation, with processes and impacts of colonisation unfolding differently across urban, remote, rural, and regional locations (Blagg \& Antony, 2019; Wendt, 2016).

\section{Situating sexual violence in RRR space and place}

Research to date suggests that while survivors share many similarities regardless of where they are geographically situated, the specificities of RRR space/place nonetheless shape experiences of GBV in particular ways. As such, the needs and experiences of survivors in RRR locations require unique consideration. We observe, however, that the overwhelming focus of current research has been on intimate partner and domestic violence. While this focus is understandable, we nonetheless know very little about sexual violence 
occurring outside of this context, and almost nothing of the everyday iterations of sexual violence, harassment, and intrusion that were at the forefront of the \#MeToo movement.

Women (and others) in RRR areas may experience disproportionately higher rates of at least some forms of GBV (Adams \& Hunter, 2007; DeKeseredy, forthcoming; DeKeseredy et al., 2016; George \& Harris, 2014; Gilmore et al., 2016; Hooker et al., 2019). Numerous authors have pointed out the ways in which the small, close-knit communities that characterise RRR locations can function as a barrier to disclosure, to survivors receiving appropriate support, and to a safe and appropriate criminal justice response being enacted (Adams \& Hunter, 2007; Carrington et al., 2013; Dietrich \& Mason, 1998; George \& Harris, 2014). Some RRR communities may be more likely to condone rigid, stereotypical gender roles, and to hold violence-supportive attitudes (Adams \& Hunter, 2007; Carrington et al., 2013; DeKeseredy, forthcoming; Ermacora, 1998; George \& Harris, 2014; Hall-Sanchez, 2014; Hooker et al., 2019; Pease, 2010). Geographical isolation also creates substantive barriers to help-seeking and support, with this isolation "drawing a veil of privacy over any violence that might occur" (Carrington et al., 2013, p. 8). Many RRR towns are underserviced, and survivors may lack access to local support (though, to some extent, this may be circumvented by access to digital technologies - Harris, 2018) or have to travel for hours to access services often with no or limited public transportation (Adams \& Hunter, 2007; Carrington et al., 2013; DeKeseredy, forthcoming; DeKeseredy et al., 2016; Ermacora, 1998; George \& Harris, 2014; Ragusa, 2017). Where such support does exist, survivors may be reluctant or unable to access it on account of fears that locals will 'gossip' (Adams \& Hunter, 2007; Carrington et al., 2013; Dietrich \& Mason, 1998; Wendt, 2016), with the small and close-knit nature of RRR areas rendering survivors highly visible (George \& Harris, 2014). Service providers and police may be well-known - potentially even close friends with a perpetrator - making it difficult to access support anonymously or confidentially (Adams \& Hunter, 2007; DeKeseredy et al., 2016; Ermacora, 1998). Survivors on remote properties may simply be unable to leave, particularly if they lack access to private transportation or money (Adams \& Hunter, 2007; Carrington et al., 2013; George \& Harris, 2014; Ragusa, 2017), are unable to leave safely, or are prevented from doing so by their perpetrator.

As we flagged earlier, there are also important intersectional considerations in an RRR context, particularly in relation to the experiences of Aboriginal women (Wendt, 2016; though many Indigenous women also live in urban areas). As Adams and Hunter (2007, p. 26) suggest, violence in Aboriginal communities must be understood in relation to "the violence perpetrated on these communities by the colonisers." For example, concerns about high rates of GBV perpetrated against Aboriginal women (and especially child sexual abuse and family and domestic violence, with Aboriginal men always already framed as the perpetrators from which women and children require white State "protection") have been used as a thin pretext for the invasive regulation and control of rural Indigenous communities through the Northern Territory Intervention (Blagg \& Anthony, 2019). More generally, Aboriginal people's mistrust of police and other government and institutions is welldocumented, while white feminism has routinely dismissed and ignored the voices and experiences of Indigenous and First Nations women (Adams \& Hunter, 2007; Blagg \& Anthony, 2019; Moreton-Robinson, 2005). As Tess Ryan (2019) has astutely pointed out, the \#MeToo movement in Australia largely excluded the voices of Indigenous women, with the movement instead (re)centring the voices of white, middle-class women. However, no research appears to have considered the representation (or lack thereof) of Indigenous survivors in media reporting on \#MeToo or sexual violence more generally - a gap that has persisted since Sutherland et al. made a similar observation in 2015. 
Our overview of the literature illustrates several important points. Firstly, media reporting on GBV can play an important role in shaping public attitudes and understandings of this issue. However, media reporting continues to reproduce myths and stereotypes about $\mathrm{GBV}$, even if there is also evidence of more progressive reporting occurring, including in the context of the \#MeToo movement. Secondly, that RRR contexts shape the perpetration and experience of GBV in particular ways. This suggests that local media in RRR locations may have a pivotal role to play in reaffirming the norms that support GBV or, conversely, to disrupt and contest them. To date, we know very little about how RRR news media portrays and constructs the issue of sexual violence generally, nor in the context of the \#MeToo movement. As such, our analysis aims to provide insight into these questions and to consider how the global \#MeToo movement translated into local contexts in Australia.

\section{Data collection and method of analysis}

In order to address the research question regarding how the \#MeToo movement impacted RRR locations in Australia, we undertook a thematic analysis of newspaper reporting on the movement. Braun and Clarke (2006, p. 79) identify thematic analysis as a "method for identifying, analysing and reporting patterns (themes) within data." Thematic analysis "involves searching across a data set...to find repeated patterns of meaning (Braun \& Clark, 2006, p. 86) ascertained through numerous choices made by researchers that require reflexivity due to the subjective nature and interpretation of the data being analysed. These choices include: 1) what researcher's judge to be a theme/pattern within the coding of data; 2) determining the extent and detail provided within the analysis; 3 ) the theoretical underpinnings of theme identification - for example Braun and Clarke (2006) suggest either 'inductive', whereby themes emerge from the data, or 'theoretical', in which the researcher's specific interest or research questions drive the coding process; 4) in terms of data analysis, a semantic or latent approach needs to be decided upon whereby researchers seek to either describe and interpret patterns within data in relation to literature in order to understand its broader implications (semantic approach), or the "underlying ideas, assumptions, and conceptualisations - and ideologies - are theorised as shaping the semantic content of the data" (latent approach) (Braun \& Clark, 2006, p. 84); and 5) researchers need to decide how they are interpreting their data either through a realist or constructivist perspective.

Before we began our thematic analysis, we undertook a process of identifying potentially relevant newspaper articles to include in the final sample. The first step involved running a search using the database Factiva with the intention of capturing all RRR Australian newspapers reporting stories that involved or included the term "\#MeToo" alongside "sexual harassment" or "sexual assault" or "rape" or "domestic violence" or "family violence" in either the title or body of the article. The initial sample comprised of 306 articles from 25 different RRR newspapers. All National daily papers and tabloids, such as The Age, The Sydney Morning Herald, The Daily Telegraph, The Herald Sun, The Australian, The Australian Broadcasting Corporation (ABC) and other major metropolitan newspapers were excluded from the sample. Articles captured in the initial sample were then narrowed down to the localities in which they were being reported on. In other words, duplicate articles that were first published in major national or international newspapers and then republished in local regional newspapers were excluded from the sample, as were the same articles published in multiple newspapers. We realise that the duplication of articles may also be reflective of the significance of the issue being reported, however, our main goal was to identify articles that were specific to the local context and newspaper in which they 
were produced. The publication dates for printed newspaper articles were kept broad from October 2017, when the \#MeToo movement was first appearing in newspaper headlines globally, through until December 2019, when the data was collected. We kept the parameters of publication dates broad to capture trends in reporting on topics related to \#MeToo, and the final articles in the sample included Opinion Editorials, Letters to the Editor, and articles written by local reporters. Appendix A at the end of this article details the final sample of articles included in this study.

The total number included in the final sample comprised of 70 articles from 18 different RRR newspapers across New South Wales, Victoria, Tasmania, Queensland, and the Northern Territory. No articles from South Australia, Western Australia, or the Australian Capital Territory (ACT) fulfilled in the inclusion criteria. Table 1 below illustrates the distribution of articles across the different states and territories included in the analysis. The majority of the articles were published in RRR Victorian Newspapers ( $n=32$ or $45.7 \%$ of the total sample), most of which came from the three major regional cities with the largest population size outside of metropolitan Melbourne (the state's capital city): Bendigo (40.6\% of the Victorian sample), Geelong (28.1\% of the Victorian sample) and Ballarat (21.8\% of the Victorian sample). A total of 15 articles were published in RRR newspapers in New South Wales (18.6\% of the total sample), and RRR newspapers in Queensland had published 11 articles on \#MeToo in some local capacity ( $15.7 \%$ of the total sample). Tasmania had nine newspaper articles represented in this sample (11.4\% of the total sample), and the Northern Territory had six $\left(8.6 \%\right.$ of the total sample). ${ }^{1}$

\section{Table 1: Distribution of articles by State and Territory}

\begin{tabular}{ccc}
\hline State & $\mathbf{n}$ & $\mathbf{\%}$ \\
\hline Victoria & 32 & 45.7 \\
New South Wales & 13 & 18.6 \\
Queensland & 11 & 11.4 \\
Tasmania & 8 & 11.4 \\
Northern Territory & 6 & 8.6 \\
\hline Total & 70 & 100 \\
\hline
\end{tabular}

The articles were primarily published in $2018(\mathrm{n}=47$ or $67.1 \%)$, with 17 published in $2019(n=16$ or $22.9 \%)$ and only seven published in $2017(10 \%)$ - perhaps indicating the amount of time it takes for global news to have a more specific local and regional impact. Reporting was also clustered around particular months. For example, October, November, and January had the highest number of articles published (11, 12, and 12 respectively), while other months were more evenly dispersed, with an average of four articles published per month outside the peak times. One explanation for the peaks in October and November is the 16 Days of Activism against Gender-Based Violence; an international United Nations initiative lead by UN Women that takes place from November $25^{\text {th }}$ until December $10^{\text {th }}$. It is clear the reporting in October across 2018 and 2019, in particular, was building up to events taking place in relation to the 16 Days of Activism in a number of newspaper articles 
\#MeToo in regional, rural and remote Australia: An analysis of regional newspapers reports profiling the movement - Loney-Howes and Fileborn

published in the Bendigo Advertiser. A further explanation for the spikes in reporting across these periods is the \#MeToo movement and its' subsequent anniversaries, although the articles themselves do not explicitly mention this. The clustering of reporting on \#MeToo around these dates is indicative of the enduring impact of the \#MeToo movement as well as other international initiatives translating into RRR locations around Australia - notably in regional Victoria.

Following Braun and Clarke's (2006) six step process for undertaking a thematic analysis, an excel spreadsheet was set up to help with the familiarisation of the data, support the initial coding, searching for, reviewing themes and defining themes. The articles were organised in the spreadsheet according to State in alphabetical order. Each article was read twice with preliminary notes recorded to help the researchers identify initial codes. These codes were then reviewed and revised three times to identify and finalise themes across the data set. As we discuss in the findings section, we identified eight overarching themes from our coding process (see Table 2 below). A theme was defined as such based on the tone of the overall article; in other words, the full contents of each article included in the sample were analysed as a whole rather than researchers searching for or identifying a variety of different themes within a specific article. We took an inductive as well as a theoretical approach to identifying themes, and subsequently, we report on all the themes in the findings section in order to present the array of examples of reporting on the \#MeToo movement in RRR newspapers in Australia. However, our primary focus is on the theme of "profiling voices speaking out about gender-based violence" guided by our literature review with respect to the problematic ways in which GBV is typically represented in news media reporting alongside the challenges associated with addressing GBV in RRR locations. A semantic analysis of articles coded under this theme was undertaken through a constructivist perspective where we sought to theorise and interpret the data in relation to the specific socio-political contexts these newspaper articles were being written and circulated. We now turn to examine the findings from the thematic analysis of the newspaper articles in our sample to explore more specifically how \#MeToo has been reported in RRR news media in Australia.

\section{Findings}

\section{Reporting themes on \#MeToo in RRR newspapers in Australia}

Our coding process identified eight themes about the ways in which \#MeToo was being reported or discussed in RRR Australia. As Table 2 indicates below, most of the themes were very small, ranging from two to nine articles in six of the eight themes, however, the themes of "Profiling voices speaking out about gender-based violence" and "Translating \#MeToo into the local context" contained significantly more articles ( $n=24$ and $n=16$ respectively). This was partly due to the authors interpreting "Profiling voices speaking out about genderbased violence" - addressed in a separate section below - in broad terms in order to capture the spectrum of voices represented in RRR news media. The larger numbers are also reflective of the numerous ways \#MeToo was made meaningful within local contexts through this reporting.

Because of its' size, we broke the theme "Translating \#MeToo into the local context" down into sub-themes to illustrate how \#MeToo was reported to have impacted the local context. These sub-themes included firstly, reporting on local events, such as "Take Back the Night" marches in both Ballarat (\#ReclaimBallarat) and Newcastle inspired by the \#MeToo 
movement. The Bendigo Advertiser also profiled a local event entitled "Talking Justice \#MeToo Seminar" held in April 2018, with the intention of presenting women with their legal options for reporting experiences in the wake of \#MeToo $(n=6$ or $37.5 \%$ of the total sample). Secondly, examples of 18.8 per cent of articles under this theme $(n=3)$ were reports on the campaign \#LetHerSpeak, which used the momentum behind the \#MeToo movement to challenge section 194K of the Evidence Act in the state of Tasmania to change the gag laws preventing survivors from speaking to the media without court approval. 18.8 per cent of articles $(n=3)$ were reporting on specific organisational or institutional responses to the issues raised by the \#MeToo movement, including workplaces seeking to address sexual harassment and regional universities addressing harassment and assault on campus. And thirdly, under this theme, we saw explicit examples of fundraisers put on by workplaces seeking to tackle the issue of sexual harassment in response to the issues raised by the \#MeToo movement. For example, two articles (12.5\% under this theme) appeared in the Geelong Advertiser (a city located 75km south-west of Melbourne) about the sexual harassment experienced by staff at the "Workers Club" - a popular live music venue. In response, the staff at the Club launched a T-shirt campaign called "don't be a d-ck" to raise awareness about sexual harassment with proceeds donated to NOW Australia. ${ }^{2}$

Table 2: Key themes in reporting on \#MeToo in RRR Australia

\begin{tabular}{lll}
\hline \multicolumn{1}{c}{ Theme } & $\mathbf{n}$ & $\mathbf{\%}$ \\
\hline Profiling voices speaking out about gender-based violence & 24 & 34.4 \\
Translating \#MeToo into the local context & 16 & 22.9 \\
Critical commentary on the \#MeToo movement & 9 & 12.9 \\
Local event indirectly related to \#MeToo & 6 & 8.6 \\
General reporting on the \#MeToo & 5 & 7.1 \\
Profiling local support services & 4 & 5.7 \\
Increases in formal reporting as a result of \#MeToo & 4 & 5.7 \\
\#MeToo linked only as a "related topic" & 2 & 2.9 \\
\hline \multicolumn{1}{c}{ Total } & 70 & 100 \\
\hline
\end{tabular}

Outside of the two major themes coded in our analysis, "Critical Commentary on the \#MeToo Movement" was noted as the third largest collection of articles $(n=9)$, most of which comprised of Opinion Editorials or Letters to the Editor. In the Geelong Advertiser, for example, two editors wrote opinion pieces about the \#MeToo movement - although their commentary suggested that the \#MeToo movement had gone too far, positioned all men as sexual predators, and that women were lying about their experiences (see Fileborn \& Phillips, 2019 for a critique of such discourse). This position was further supported by several letters to the editor. However, other op-eds, for instance, two published in the Daily Examiner out of Grafton (a small city with a population of 19, 078 in the Northern Rivers Region of New South Wales), used the \#MeToo movement as an opportunity to criticise the lack of political willingness in Australia in general to address violence against women. One of these opinion pieces went further to highlight the potential negative impact the \#MeToo movement may 
\#MeToo in regional, rural and remote Australia: An analysis of regional newspapers reports profiling the movement - Loney-Howes and Fileborn

have on survivors still living with perpetrators whose behaviour might worsen with the flurry of attention given to GBV and harassment.

The next largest theme was newspaper articles reporting on local events that were indirectly related to \#MeToo, but the reporters positioned them as timely because of the \#MeToo movement $(n=6)$. For example, the Launceston Examiner in Tasmania reported in March 2018 that Tim Winton (a prominent Australian author) was promoting one of his books about domestic violence at the Tamar Valley Writers Festival in order to start a conversation about the issue in the era of \#MeToo. Although these articles were only indirectly related to the \#MeToo movement, the mention of "\#MeToo" indicates that the term may be a shortcut now used by journalists for referencing violence against women.

The theme "General Reporting on the \#MeToo movement" included articles that were not necessarily specific to the local area but were focused on broader issues that emerged in response to the movement $(n=5)$. These included articles written about the Gillette advertisement, for example, that sought to encourage men to be the best man they can and suggested that the \#MeToo movement might help to shift some of the problematic attributes associated with hegemonic masculinity. Other articles under this theme were reporting more broadly about gender inequality as the driving force behind the prevalence of GBV in Australia.

A further theme we encountered was using the \#MeToo movement for the purposes of "Profiling of local support services" $(n=4)$, with a particular focus on the increased pressure placed on under-resourced local services due to the increased demand created by the \#MeToo movement. As we noted in the literature review, many RRR communities are already underserviced and unable to meet the demands and needs to survivors in their local communities. While it is positive that the \#MeToo movement has encouraged survivors to seek support and local reporting is drawing attention to the demand for services in RRR Australia, in the absence of increased government financial support this has unfortunately placed greater strain on an already overloaded system.

We noted a small number of articles in RRR Tasmanian newspapers detailing increases in official reports of sexual assault to local police following the \#MeToo movement $(n=4)$. This focus in Tasmania may have been due to the impact of the campaign \#LetHerSpeak mentioned earlier under the theme "Translating \#MeToo into the local context." One article paraphrased the Executive Officer from Support, Help, Empowerment (a support service in Tasmania) suggesting the increase in survivors reporting could be linked to "reduced community tolerance of sexual assault and victims feeling more compelled to come forward" ("Sexual Assaults Rise", Launceston Examiner, 26 ${ }^{\text {th }}$ January, 2018). The articles discussing the increases in reports of sexual assault suggest that the \#MeToo movement has perhaps made victim-survivors more comfortable coming forward to report sexual assault, proclaiming that the \#MeToo movement had taken the stigma out of sexual violence.

Finally, we also collated articles under our final theme "MeToo noted only as a related topic" if they were not specifically about \#MeToo but the content of the article was on a relevant topic and "\#MeToo" was mentioned in the article $(n=2)$. For example, one article that appeared in the Newcastle Herald profiled a local service provider and activist supporting women leaving violent relationships after her exposure to domestic and family violence in Nepal. The subject of the article had met with Alyssa Milano and the article noted that she started the "Me Too" hashtag, which is how the story was made relevant to the 
\#MeToo movement. This perhaps again points to \#MeToo being used as a discursive shortcut to refer to GBV more generally.

Within the themes identified through the content analysis, it is evident that reporting on the \#MeToo movement in RRR Australia captured a spectrum of sexually violent experiences. This is significant because although the \#MeToo movement sought to explicitly highlight the prevalence of sexual harassment and sexual violence experienced by women, much of the existing literature and knowledge about violence against women in RRR contexts focuses on domestic and family violence. As Table 3 demonstrates, the majority of reporting was on both sexual harassment and sexual violence $(n=52$ or $74.3 \%$ of the total sample) with only a small number of reports that were solely about domestic and family violence $(n=10$ or $14.3 \%$ of the total sample).

Table 3: Reporting on different types of gender-based violence

\begin{tabular}{llc}
\hline \multicolumn{1}{c}{ Type of gender-based violence discussed } & n & \% \\
\hline BOTH sexual harassment and sexual violence & 23 & 32.9 \\
ONLY sexual assault, sexual violence or rape & 21 & 30 \\
ONLY domestic and family violence & 10 & 14.3 \\
ONLY sexual harassment & 8 & 11.4 \\
$\begin{array}{l}\text { Domestic and Family Violence, sexual assault, sexual violence or } \\
\text { rape, and sexual harassment }\end{array}$ & 7 & 10 \\
$\begin{array}{l}\text { Domestic and Family Violence and sexual assault, sexual violence or } \\
\text { rape BUT NOT sexual harassment }\end{array}$ & 1 & 1.4 \\
\hline Total & 70 & 100 \\
\hline
\end{tabular}

The broad representation of different forms of violence against women in reporting on the \#MeToo movement in RRR Australia draws our attention to the full continuum of GBV experienced in RRR locations (see Kelly, 1988). Reporting on sexual harassment and sexual violence in RRR location is indicative that the specific focus of the \#MeToo movement resonates with these communities, and reflects a concern or perceived need to acknowledge and represent sexual harassment and violence in RRR locations, given the general silence on forms of sexual violence occurring outside of a domestic and family violence context. In other words, \#MeToo has provided an opportunity to represent other iterations of sexual violence in a way that begins to capture the full range and scope of survivors' experiences in a range of different locations, and we now turn to our analysis of reporting on the theme of "Profiling voices speaking out about gender-based violence" to examine this in closer detail.

\section{Profiling voices speaking out about GBV in RRR communities in the wake of \#MeToo}

The themes identified through our coding process, content and thematic analysis demonstrate that the \#MeToo movement was represented in RRR newspaper reporting in 
diverse, meaningful, and specific ways. Moreover, the reporting on sexual violence and harassment has highlighted the need to focus on these specific areas in addition to domestic and family violence, which is disproportionally prevalent in existing research and policy responses. However, as indicated in Table 2 above, the largest clustering of reporting on \#MeToo was focused on "Profiling voices speaking out about gender-based violence" $(n=24$ or $34.4 \%)$.

The profiling of survivors' voices has long been deployed as a political tool by feminist activists since at least the 1970s who sought to "break the silence" that surrounds sexual violence, with many heavily invested in the transgressive and transformative potential of survivor speech in particular to shift cultural, political and legal responses to rape in the hope that this would lead to its elimination (Alcoff, 2018; Alcoff \& Grey, 1993; Heberle, 1996; Serisier, 2018). Yet despite nearly four decades of deliberate and concerted attempts to speak out - collectively and individually - this has not ended sexual violence (Fileborn \& LoneyHowes, 2019; Serisier, 2018). Although speaking out has had a significant cultural impact on drawing attention to the prevalence of sexual violence, there has been significant criticism and backlash directed at many survivors who have spoken out (Alcoff, 2018; Fileborn \& Loney-Howes, 2019; Serisier, 2018). In addition, it has not contributed in any clear way to reducing the number of survivors, nor has it eliminated the stigma associated with being a rape victim (Serisier, 2018, p. 12). Moreover, there are discursive parameters that shape the conditions under which experiences sexual violence may be discussed in the public sphere, and subsequently whose experiences may be considered legitimate when speaking out (Serisier, 2018; author's work). These discursive parameters have been heavily shaped and reinforced through the way news media has reported on and profiled the voices of survivors (see Horeck, 2004; Serisier, 2005; 2018). As we discussed in the literature review, historical and contemporary profiling of survivors' voices in news media have typically sought to sensationalise sexual violence and privilege voices whose experiences reflect tropes of sexual chastity and blamelessness. Yet very little is known about the representation of sexual violence in RRR newspapers or the profiling of voices speaking out about GBV.

Table 4 below illustrates the different voices profiled in news media reporting in the RRR articles in our sample, with local support services - be it CEO's, other leaders or employees - accounting for the largest proportion of voices profiled speaking out about GBV ( $n=10$ or $41.7 \%$ ), followed by survivors speaking out $(n=7$ or $29.2 \%$ ).

Table 4: Profiling voices speaking out about gender-based violence in RRR contexts

\begin{tabular}{lll}
\hline Theme & $\mathbf{n}$ & $\mathbf{\%}$ \\
\hline Local support service CEO/employees voices & 10 & 41.7 \\
Survivor's voices & 7 & 29.2 \\
Activist or community member's voices & 2 & 8.3 \\
Aboriginal women's voices/experiences/support services & 2 & 8.3 \\
Other & 3 & 12.5 \\
\hline Total & 24 & 100 \\
\hline
\end{tabular}


Given the colonial geopolitical context of Australia and the critiques of the whitewashed nature of the \#MeToo movement, we were particularly keen to examine the extent to which Aboriginal and Torres Strait Islander women's experiences or voices in any capacity were being represented in our sample. However, there were only two articles that explicitly referenced the voices, experiences of or support services associated with Aboriginal women - and these were both from the Northern Territory where statistically more Aboriginal people reside. The articles representing Aboriginal women and support services drew attention to the lack of recognition of the work carried out by Aboriginal women to prevent violence against women, reflecting the critiques of feminist anti-violence work in Australia raised by Tess Ryan (2019) and sought to bolster their presence. For example, one article profiled the work of the Tangentyere Family Violence Prevention Program located in Alice Springs (a town of approximately 25, 000 people located in central Australia) that began in 2014, highlighting the importance of responding to GBV in more culturally specific ways ("Empowering our women", published in the Centralian Advocate, 3 August, 2018). Another article explicitly tapped into some of the issues identified early on in the \#MeToo movement relating to the co-option of the work of Tarana Burke, and indeed, was highly critical of white Australian feminist journalist Clementine Ford's inability to centre Aboriginal and Torres Strait Islander women's experiences in her writing in the wake of \#MeToo ("So much absurd chatter", published in the Centralian Advocate, 26 June, 2018). As we highlight below in our discussion section, capturing these perspectives are vital for drawing our attention to the work being done in RRR communities led by Aboriginal women. This small sample does demonstrate efforts to push back against the invisibility or problematic representations of Aboriginal women in news media reporting on sexual violence in Australia more broadly (see Ryan, 2019). Yet news media representations of survivors' voices and support services speaking out in RRR in Australia remain predominantly white, perpetuating the erasure of First Nations women's experiences and specific needs in addressing GBV.

In terms of articles featuring the voices of local support service CEOs or employees, some of this commentary was around the specific challenges associated with addressing sexual violence in RRR contexts, namely intergenerational abuse, which was profiled in an article published in the Bendigo Advertiser on December 8, 2018. Although intergenerational abuse has been noted in the literature as an issue in Aboriginal communities as one manifestation of intergenerational trauma caused by the enduring legacies of colonisation (Black et al., 2018; Blagg et al., 2018; Guggisberg, 2019), its mention here in relation to an issue for RRR Australia outside Aboriginal communities is significant. The Royal Commission into Institutional Responses to Child Sexual Abuse, which ran from 2013-2017, identified the intergenerational transmission of child sexual abuse as a cycle needing direct and immediate intervention (Wright et al., 2017). No doubt, the challenges associated with addressing a variety of forms of intergenerational violence in RRR Australia call for specific intersectional approaches, including attention to class, race, and sexuality, and requires immediate scholarly and policy attention. However, outside of this specific focus on intergenerational abuse, most articles profiling the voices of those working for support services described more generally the need to believe and empower survivors when they come forward, to challenge gender stereotypes, and the role that young people play in the prevention of violence, rather than the specific challenges that may be facing survivors or preventing sexual violence in RRR communities. 
One exception to this broad approach in addressing sexual violence was an article, also published in the Bendigo Advertiser on September 11, 2018, discussing the challenges survivors of sexual harassment in RRR contexts face when reporting or speaking out about their experience(s). Specifically, the support service worker featured in the article stated that:

Workers in regional areas often have less alternative work options and are fearful of losing work if they complain, which makes them more vulnerable and less likely to complain about unlawful conduct.

Such comments begin to draw attention to the challenges associated with addressing sexual harassment in RRR geographical contexts. Certainly, there are substantive barriers to reporting and seeking support for workplace harassment in general, with research from the Australian Human Rights Commission illustrating that the vast majority of victims do not make a formal complaint, and those who do can face negative ramifications such as being ostracised from the workplace or losing their job (AHRC, 2018). However, the comments above demonstrate how these barriers can be heightened in an RRR context, with some Australian RRR locations facing high levels of unemployment and poverty (Vinson, 2007). As such, these representations reveal some of the specific harms survivors of sexual harassment and violence may face in terms of their economic vulnerabilities, and the extent to which local 'gossip networks' - described earlier in our literature review - may further stymie a survivor's chances of gaining employment elsewhere. It is commendable that such specific challenges relating to the sexual harassment in RRR Australia are being outlined in news media reporting, and further research is needed to understand these from the perspectives of survivors.

In contrast to all the other articles published profiling the voices of support services encouraging survivors to come forward, an article published in the Burnie Advocate - located in Burnie, part of regional Tasmania - on November 20, 2017, describes the risks associated with speaking out online in the \#MeToo chorus, cautioning against it because it can damage police investigations particularly if they named offenders. The report draws on an interview with the CEO of SHE (Support, Help, Empowerment - a peak body support service and advocacy group in Tasmania), in which the \#MeToo movement is described as a "progressive, but problematic initiative." The CEO suggested "survivors need to find support offline", and strongly encouraged survivors to report to police rather than take matters into their own hands. Research predating the \#MeToo movement indicates that digital communications technologies are important tools for survivors of sexual violence and domestic and family violence, helping to create and sustain supportive communities that are often not available offline (Fileborn, 2014; Harris, 2018; Loney-Howes, 2018; Mendes et al., 2019; O’Neill, 2018; Powell, 2015; Salter, 2013). However, in sharing experiences online survivors also risk being identified by others in their communities, which may have negative consequences. Indeed, it is possible that "gossip networks" and the "tight knit" nature of RRR communities may ostracise or result in further harms for survivors including their personal safety, especially if the perpetrator is named and well-liked (see Loney-Howes, forthcoming, p. 133). Yet, these risks are not necessarily limited to survivors in RRR areas, and it remains unclear as to how sharing an experience online might negatively affect rural survivors in specific ways. However, as we move on to discuss below in relation to specific instances of news media representing survivors' voices in RRR Australia, the \#MeToo movement has been instrumental in shifting the stigma associated with sexual violence and enabled (some) survivors - regardless of geographic location - to share their stories. 
Our coding process identified seven articles published that specifically featured the voices of survivors speaking out about their experiences, and here we unpack three that centre the survivors' narratives in their own words. We focus our analysis on these three because they are the only articles in the sample that entirely feature survivor's voices. In other words, a reporter had not broken up, manipulated, or attempted to interpret the survivor's voice, and the article is in the survivors' words only. This privileging of survivors' voices in such journalist practices enables survivors to construct, interpret and make meaningful their experiences in their own terms without the presence of an expert mediating and validating their experience (Palmer-Mehta, 2018).

In many ways, the themes discussed by survivors in these media representations reflect the broader challenges and logics that sit behind wanting to share experiences of sexual violence regardless of geographic location, with our sample reflecting two key themes. Firstly, the safety provided by the \#MeToo movement enabled survivors to share their experiences and in doing so challenged the ways many are shamed into silence. Secondly, the desire to highlight and therefore contest the cultural and social contexts that enable sexual violence to take place. For example, an article written by a local journalist published in the Northern Territory News on October 21, 2017 about her own experiences of sexual violence explicitly sought to shift the shame and blame back onto perpetrators, and in doing so directly intervenes in the victim-blaming discourses that seek to maintain the silence of survivors. In the article, the journalist notes the fear associated with not wanting friends and family to know she was a survivor but nonetheless decided to document all the times she can say "Me Too" to highlight the prevalence of sexual violence. Specifically, she said: "almost every woman I know has been the victim of sexual assault or harassment... [and] it's important that that my brothers, mum, dad, boyfriend, friends and colleagues and you all know about these horrific instances [I had]." The article concludes with the author stating that the while these stories are "shameful", the shame belongs to the perpetrators, not survivors.

Similar to the piece published in the Northern Territory News, an article written by a local reporter appeared in the Shepparton News on October 19, 2017 about her experience of sexual harassment in a small rural town in Queensland in March 2016. She describes how she confronted the perpetrator: "I grabbed him by the collar, pushed him up against the wall." She then said to him: "Don't you ever touch a woman who hasn't asked to be touched by you ever again." The reporter then goes on describe how "speaking back" to the perpetrator made her feel powerful, and that the \#MeToo movement has enabled survivors to take back their voices and prompted a discussion to dismantle assumptions that women are not the property of men - as the excerpt below highlights:

It was the first time I felt powerful in any kind of harassment situation, because I was finally taking back all of the times I'd felt humiliated or traumatised by something a man did... However serious the situation...it all leads back to the same notions: culture, entitlement and respect. The \#MeToo hashtag campaign has highlighted the magnitude of sexual harassment and abuse, and it showed how finally a group of women were able to tell their story, and be believed by the world, in the aftermath of the Harvey Weinstein scandal. They took back their voices. But this isn't about women taking back what shouldn't have been taken in the first place. It's about starting a discussion that women aren't property, they aren't there to touch, or own or tell what to do. 
Finally, an article in the Bendigo Advertiser published on November 24, 2018, described how "Jodie" (not her real name) felt compelled to report her experience of rape as a teenager. Jodie's comments again draw attention to the power of digital community in supporting and emboldening survivors to be able to speak out. Jodie explicitly makes this connection in her comments, saying that "the \#MeToo movement has helped me by providing me support", from which she could "take strength" and know that she is not alone, disrupting the social isolation and silence that can be particularly acute for survivors in RRR areas.

As we noted in the literature review, previous research suggests that the "tight-knit" nature of rural communities can act as a barrier to disclosure, with these communities often working to uphold patriarchal, homosocial relations that support and minimise the perpetrator's actions. Profiling survivors' voices through RRR newspaper reporting demonstrates the power and potential of the support networks generated through the \#MeToo movement. Although these survivors' voices are not manifesting through the hashtag - as so many did in the days and weeks following the movement's emergence - the cumulative impact of millions of survivors sharing experiences nonetheless provided them with the solidarity needed to speak out enabled by progressive journalist practices. That said, it is notable that two of the three individual survivor accounts featured here were written by journalists, rather than 'general' members of the public - and those that were, used pseudonyms to protect their identities. While it is not possible to draw firm conclusions based on this sample, this may nonetheless point to a reluctance to profile the voices of survivors in RRR locations by news media outlets, and those which have direct access to a media platform and significant control over the narrative going out into the public sphere. Thus, at the very least, we must question whose voices have been privileged, and what silences remain within RRR media discourse. Indeed, the absence of direct survivor voices and experiences is striking in a sample of media reporting based on a global movement premised on centring survivors' voices and experiences. Moreover, the lack of focus or incorporation of a diverse array of survivors, including Aboriginal survivors but also survivors who identify as LGBTQI+, are older, who may have disabilities or even those who live in very remote locations, is evident in this sample. As we noted earlier in this article, the \#MeToo movement, along with anti-violence against women activism in general has faced regular criticisms for failing to account for diversity in terms of whose voices are heard, as well as the complex and intersectional nature of experiences of violence. It seems that in RRR contexts in Australia these issues relating to representation are even further entrenched, thus we now turn to discuss the implications for these findings from our analysis.

\section{Discussion}

In this article, we sought to examine how news media has reported on the \#MeToo movement in RRR Australia with an in-depth focus on the profiling of voices speaking out about GBV. Our analysis drew attention to the breadth of GBV discussed in RRR media reporting, with sexual harassment and assault the most commonly discussed iteration of this violence. Contrary to the almost-exclusive focus on domestic and family violence in current scholarship, media reporting reflected the full continuum of sexual violence in RRR communities, and we call for future research to better encapsulate this. Although we have only provided a small snapshot of the different approaches to profiling voices speaking out about GBV in RRR newspapers, our findings here suggest that the \#MeToo movement impacted RRR communities in Australia in profound ways. While many of the voices profiled within newspaper reports reflected broader challenges associated with addressing 
sexual violence and harassment, there were some insights - albeit small ones - into the specific issues experienced by RRR contexts in Australia, such as intergenerational abuse. The articles in our sample also gave voice to practitioners and drew attention to the issue of sexual and GBV in RRR locations, including the challenges faced by under-resourced service providers in the wake of \#MeToo. Although we have not had the space to explore in more detail the ways in which \#MeToo translated into local contexts in RRR Australia, it was clear from the newspaper articles that some local services and activists were able to leverage \#MeToo to highlight local issues, such as the Tasmanian gag laws, that until recently prevented survivors from speaking out about their experiences.

Of course, there is only so much we can gauge about the impact of \#MeToo and survivors' experiences in RRR contexts in Australia from analysing these newspaper reports. There is little insight offered into the specific challenges faced by survivors, although our analysis of news reports under the theme "Profiling local support services" reveals the strain the \#MeToo movement placed on RRR support services to provide adequate care for those who sought help. Although there was no explicit commentary on the barriers faced by survivors in RRR locations speaking out, it is fair to assume that there are some shared or similar barriers for survivors of both sexual and domestic violence (for example, shame, embarrassment, fear of not being believed, or a lack of access to appropriate support services). That said, there are also important differences between sexual violence compared to domestic and family violence (Wendt, 2016). Although we acknowledge that sexual violence is often a form of abuse experienced in the context of domestic and family violence, sexual assault and harassment also occur in a broad range of contexts including the workplace, entertainment and leisure settings, the street, and so forth. Sexual assault and harassment may be perpetrated in distinct relational contexts, such as dating, colleagues, acquaintances, and strangers (particularly for street-based harassment). As a result, there may be distinct barriers to disclosure and speaking out that are not captured in the literature on domestic and family violence in RRR contexts. To date, there is virtually no research on experiences of everyday harassment and intrusion in RRR areas outside of the workplace (Saunders \& Easteal, 2012), though these experiences were arguably a central focus on the \#MeToo movement. It is not possible to capture these complexities by undertaking a media analysis alone, and there is a clear need for future research to address the full continuum of GBV in RRR localities, particularly forms of 'everyday' violence and harassment.

Although the goals of the \#MeToo movement have never been fully articulated, the collective enunciation of experiences, along with the recognition of the widespread nature and harm caused by sexual violence have to a significant degree been the outcomes of the movement. It is clear from our analysis that the \#MeToo movement may have provided survivors of sexual violence in RRR locations with a framework and the safety of numbers to speak about their experiences in the press. However, we know little about how RRR survivors have actually participated in or engaged with \#MeToo posts online or the extent to which it has been meaningful to themselves on a personal level as no research has been published on the topic. Subsequently, nothing is known about the specificities of how these survivors might have gained a sense of strength and solidarity from the movement. Moreover, we know nothing of the RRR survivors who were unable or unwilling to engage with \#MeToo or those who did not experience a sense of belonging and solidarity with other survivors who participated. While some of these barriers may be shared by survivors across geographic locations, it is equally possible that living in an RRR area presented unique challenges to participation that have not been captured here, in line with previous research on domestic and family violence. Social media is also used in the perpetration of sexual and 
intimate partner violence (see George \& Harris, 2014; Powell \& Henry, 2017; Senior et al., 2017), so this further complicates its use for speaking out publicly - digital spaces are not necessarily safe ones for survivors living in RRR areas, particularly if their perpetrators also live locally. Again, the potential ramifications for speaking out online (or offline) remain unacknowledged in this media discourse. What, for example, happens to a survivor who speaks out online in a way that identifies either herself/themselves or their perpetrator? While their digital networks may provide support and solidarity, this is far from certain (Fileborn, 2017; Fileborn \& Loney-Howes, 2020; Salter, 2013), as is the response from any members of the local community who view a digital disclosure.

The question of which RRR voices were excluded from RRR reporting on the \#MeToo is perhaps answered implicitly through some notable silences. Aboriginal voices were not present outside of regions where they are already over-represented, namely the Northern Territory, and sought to challenge the dominance of white women's voices and activism who overlooked, ignored, or appropriated the voices of Aboriginal women in Australia (see Ryan, 2019). These critiques are reminders of the continued failure in mainstream feminism as well as in representations of voices profiled in news media to capture the experiences of and challenges faced by Aboriginal and Torres Strait Islander survivors and advocates. Further, none of the articles in our sample profiled issues relating to the LGBTQ+ community in RRR contexts or acknowledged that LGBTQ+ communities experience disproportionately high rates of sexual and other violence (LGBTIQ Domestic and Family Violence Interagency \& CSRH, 2014). This silence reflects a broader failure of the \#MeToo movement to be inclusive of LGBTQ+ survivors (Ison, 2019), in addition to other intersectional concerns. The complete absence of discussion of LGBTQ+ survivors in our sample suggests that RRR media reporting on \#MeToo further perpetuated the erasure of queer sexual violence. This silence may have important implications in shaping who is viewed as a victim-survivor in RRR contexts (and, indeed, whether LGBTQ+ people are positioned as existing and belonging within RRR communities), with follow on consequences for the provision of inclusive and appropriate support services.

It remains important not to collapse the differences within and between rural, regional, and remote locations; something we inevitably do in this piece. As noted earlier, RRR locations are far from homogeneous, and we cannot assume that the \#MeToo movement resonated in all RRR locations to the extent that we have reported on this article. Although many of our observations noted positive shifts in how the \#MeToo movement and GBV more broadly were represented in print media, much of the newspaper coverage we engaged with in our analysis was still from large regional areas on the peripheries of major urban centres, specifically Sydney, Brisbane, and Melbourne. To a large extent, this is reflective of the distribution of population in Australia whereby 89 per cent of the population lives in urban areas, of which 65 per cent of people are located in capital cities (Hugo et al., 2015). However, this may also be illustrative of shifting characteristics and demographics within these regional communities. For example, some of these larger regional centres are reasonably progressive contrary to assumptions that RRR communities are conservative in nature. Many, such as Bendigo (Victoria), Ballarat (Victoria), Geelong (Victoria), Armadale (NSW) and Newcastle (NSW) amongst others, have established university communities, and some have undergone recent "revivals" with state governments investing in parts of regional Australia to encourage "tree changes" and boosting local economies (Wear, 2012; Wheeler \& Lang, 2001). There has also been a concerted effort in the state of Victoria to establish regional co-located multidisciplinary centres for responding to sexual violence that incorporate police, hospital forensic teams, and support services 
(https://www.police.vic.gov.au/sexual-offences-and-child-abuse-investigationteams\#multidisciplinary-centres, see also Hooker et al., 2019). The changing makeup of RRR Australia, combined with increased efforts to address GBV in regional locations may be resulting in a shift in attitudes about GBV within parts of RRR Australia, further supported by specialist reporters located in these areas who are able to appropriately represent the challenges and complexities associated with sexual violence - and present these as important local issues. Nonetheless, future research ought to consider unpacking how survivors' experience speaking out across different RRR contexts to consider the dynamics of larger regional localities as well as smaller and more remotely located communities - something a media analysis alone cannot capture.

\section{Conclusion}

In this article, we have demonstrated the ways the \#MeToo movement was made meaningful in RRR Australia through a thematic analysis of 70 articles from RRR newspapers reporting on the \#MeToo movement. Our analysis and discussion were positioned in relation to the literature on the problematic ways sexual violence and survivors are routinely represented newspapers, aligning this with the challenges associated with addressing GBV in RRR areas. Overall, our analysis demonstrated a progressive approach to reporting on sexual violence and harassment, with the sample illustrating a variety of different ways the movement was made meaningful and impactful in local contexts. For example, journalists reported on local activist campaigns inspired by the \#MeToo movement as well as documented an increase in the formal reporting of sexual violence and harassment. Our findings section more specifically investigated the profiling of voices speaking out about GBV in RRR newspapers. We noted that examples of voices speaking out about GBV sought to connect their discussions and perspectives to broader, non-geography specific claims about gender inequality and to challenge the stigma and shame that accompanies sexual violence, rather than discuss the specificities associated with responding to sexual harassment and violence in RRR Australia. However, there were mentions of geography-specific issues associated with addressing sexual violence in these locales, such as intergenerational abuse and sexual harassment represented in these media reports. Although these examples were only mentioned briefly in two articles we analysed, their appearance demonstrates that there are indeed specific challenges in RRR communities that require immediate research and policy attention that pays particular attention to the intersections between workplace harassment, geographic location, family networks, poverty/socio-economic status, and race. Further research is needed to explore and unpack these issues in order to more fully understand the challenges and complexities of sexual violence and harassment in RRR locations not just in Australia but globally; using the \#MeToo movement as a starting point may prove fruitful in engaging survivors in RRR locations.

Although this article has demonstrated that the \#MeToo movement has to some degree been able to transcend the urban-regional/rural divide in Australia, the profiling of voices speaking out about GBV continues to be those who are mostly white, heterosexual women. This continual failure to account for and represent diverse experiences in mainstream discussions about sexual violence (and GBV more broadly) perpetuates the neo-colonial erasure of Aboriginal survivors' voices and the tireless efforts of support services run by Aboriginal women (Ryan, 2019). The lack of attention given to LGBTQ+ voices and experiences was also missing from our analysis of RRR newspaper articles. As such, the voices profiled in news media reporting on the \#MeToo movement in RRR Australia have entrenched the investment in the voices of white, young, heterosexual women, also reflected 
within mainstream support services in these regions. Yet, as we have flagged throughout, there are limitations to the study design and sample, and we do not suggest that the findings presented here are generalisable. Qualitative research with survivors from RRR areas is clearly required to provide an in-depth understanding of the barriers to and complexities of speaking out, and to give voice to the experiences and perspectives of marginalised groups who are less likely to be featured in news media reporting. Nonetheless, the media analysis conducted in the present study provides important initial insights into how the \#MeToo movement itself was understood, translated within, and made meaningful in RRR communities in Australia.

\section{Endnotes}

${ }^{1}$ As we noted in the literature review, defining "regional, rural and remote" contexts can be quite difficult and in the Australian context can be defined based on population, postcodes, and proximity to capital cities (Harkness et al., 2015). Because of their small population numbers, all of Tasmania and the Northern Territory are considered part of "regional, rural or remote" Australia, and we have subsequently retained articles from state capitals and other major urban centres in these areas as a result.

${ }^{2}$ NOW Australia was an organisation was established in the wake of \#MeToo to provide support to survivors of workplace harassment. It faced significant critique in relation to its politics, failure to provide tangible support to survivors, and financial operations, and no longer exists (see Ryan \& Rushton, 2019). 


\section{References}

Adams, R., \& Hunter, Y. (2007). Surviving justice: Family violence, sexual assault and child sexual assault and child sexual assault in remote aboriginal communities in NSW. Indigenous Law Bulletin, 7(1), 26-28.

Alcoff, L. M. (2018). Rape and resistance. Polity Press.

Alcoff, L., \& Gray, L. (1993). Survivor discourse: Transgression or recuperation? Signs: Journal of Women in Culture and Society, 18(2), 260-290. https://doi.org/10.1086/494793

Australian Bureau of Statistics. (2001). Census data. https://www.abs.gov.au/websitedbs/censushome.nsf/home/historicaldata2001?opendo cument

Australian Human Rights Commission. (2018). Everyone's business: Fourth national survey on sexual harassment in Australian workplaces.

https://www.humanrights.gov.au/sites/default/files/document/publication/AHRC_WORKPL ACE_SH_2018.pdf

Black, C., Frederico, M., \& Bamblett, M. (2019). Healing through connection: An Aboriginal community designed, developed and delivered cultural healing program for Aboriginal survivors of institutional child sexual abuse. The British Journal of Social Work, 49(4), 1059-1080. https://doi.org/10.1093/bjsw/bcz059

Blagg, H., \& Anthony, T. (2019). Decolonising criminology: Imagining justice in a postcolonial world. Palgrave Macmillian. https://doi.org/10.1057/978-1-137-53247-3

Blagg, H., Williams, E., Cummings, E., Hovane, V., Torres, M., \& Woodley, K. N. (2018). Innovative models in addressing violence against Indigenous women: Final report (ANROWS Horizons 01/2018). ANROWS.

Boyle, K. (2019). \#MeToo, Weinstein and Feminism. Palgrave Pivot. https://doi.org/10.1007/978-3-030-28243-1

Braham, L. (2018, August 3). Empowering our women. Centralian Advocate. https://www.territorystories.nt.gov.au/jspui/bitstream/10070/301444/13/Centralian\%2 0Advocate_20180803_page13_Centralian_News_13.PDF.

Braun, V., \& Clarke, V. (2006). Using thematic analysis in psychology. Qualitative Research in Psychology, 3(2), 77-101. https://doi.org/10.1191/1478088706qp063oa

Breen, M. D., Easteal, P., Holland, K., Sutherland, G., \& Vaughan, C. (2017). Exploring Australian journalism discursive practices in reporting rape: The pitiful predator and the silent victim. Discourse \& Communication, 11(3), 241-258. https://doi.org/10.1177/1750481317697858 
\#MeToo in regional, rural and remote Australia: An analysis of regional newspapers reports profiling the movement - Loney-Howes and Fileborn

Brownmiller, S. (1975). Against our will: Men, women and rape. Simon \& Schuster.

Carrington, K., Donnermeyer, J. F., \& DeKeseredy, W. S. (2014). Intersectionality, rural criminology, and re-imagining the boundaries of critical criminology. Critical Criminology, 22, 463-477. https://doi.org/10.1007/s10612-014-9257-0

Carrington, K., McIntosh, A., Hogg, R., \& Scott, J. (2013). Rural masculinities and the internalisation of violence in agricultural communities. International Journal of Rural Criminology, 2(1), 3-24. https://doi.org/10.18061/1811/58849

Carrington, K., McIntosh, A., \& Scott, J. (2010). Globalization, frontier masculinities and violence: Booze, blokes and brawls. British Journal of Criminology, 50(3), 393-413. https://doi.org/10.1093/bjc/azq003

D'Agostino, E. (2018, December 8). Meet the workers bringing hope to sexual assault survivors. Bendigo Advertiser. https://www.bendigoadvertiser.com.au/story/5798714/meet-the-workers-bringinghope-to-sexual-assault-survivors/.

DeKeseredy, W. S. (2019). Intimate violence against rural women: The current state of sociological knowledge. International Journal of Rural Criminology, 4(2), 312-331. https://doi.org/10.18061/1811/87904

DeKeseredy, W. S., Hall-Sanchez, A., Dragiewicz, M., \& Rennison, C. M. (2016). Intimate violence against women in rural communities. In J. Donnermeyer (Ed.), The Routledge International Handbook of Rural Criminology (pp. 171-179). Routledge. https://doi.org/10.4324/9781315755885-20

Dietrich, L., \& Mason, R. (1998). There's no full-on rape here: Confronting violence against women in a country town. Women Against Violence: An Australian Feminist Journal, $4,8-14$.

Donnermeyer, J. F. (2016). Introduction to the international handbook of Rural Criminology. In J. Donnermeyer (Ed.), The Routledge International Handbook of Rural Criminology (pp. 1-10). Routledge. https://doi.org/10.4324/9781315755885-1

Donnermeyer, J. F. (2017). The place of rural in a Southern Criminology. International Journal for Crime, Justice and Social Democracy, 6(1), 118-132. https://doi.org/10.5204/ijcjsd.v6i1.384

Donnermeyer, J. F., \& DeKeseredy, W. (2008). Toward a rural critical criminology. Southern Rural Sociology, 23(2), 4-28.

Dwyer, T., \& Muller, D. (2016, December 12). FactCheck: Is Australia's level of media ownership concentration one of the highest in the world. The Conversation. https://theconversation.com/factcheck-is-australias-level-of-media-ownershipconcentration-one-of-the-highest-in-the-world-68437. 
Easteal, P., Holland, K., Breen, M. D., Vaughan, C., \& Sutherland, G. (2019). Australian media messages: Critical discourse analysis of two intimate homicides involving domestic violence. Violence Against Women, 25(4), 441-462. https://doi.org/10.1177/1077801218780364

Elliott, I. (2017, November 19). Law society, SHE warn against online naming and shaming. Burnie Advocate. https://www.theadvocate.com.au/story/5064182/harassment-sharedonline/.

Ermacora, J. (1998). It's different in the country... Women against violence: An Australian Feminist Journal, 4, 36-44.

Fileborn, B. (2014). Online activism and street harassment: Digital justice or shouting into the ether? Griffith Journal of Law and Human Dignity, 2(1), 32-51.

Fileborn, B. (2017). Justice 2.0: Street harassment victims' use of social media and online activism as sites of informal justice. British Journal of Criminology, 57(6), 14821501. https://doi.org/10.1093/bjc/azw093

Fileborn, B., \& Loney-Howes, R. (2019). \#MeToo and the Politics of Social Change. Palgrave Macmillan. https://doi.org/10.1007/978-3-030-15213-0

Fileborn, B., \& Loney-Howes, R. (2020). Using social media to resist gender violence. In E. Erez \& P. Ibarra (Eds.), Oxford Encyclopedia of International Criminology. Oxford University Press. https://doi.org/10.1093/acrefore/9780190264079.013.613

Fileborn, B., \& Phillips, N. (2019). From 'Me Too' to 'Too Far': Contesting the boundaries of sexual violence in contemporary activism. In B. Fileborn \& R. Loney-Howes (Eds.), \#MeToo and the Politics of Social Change (pp.99-115). Palgrave McMillan. https://doi.org/10.1007/978-3-030-15213-0_7

Finkelstein, R., Ricketson, M., Tiffen, R., Papandrea, F., Walker, K., Young, C., \& Hill, G. (2012). Report of the independent inquiry into the media and media regulation. Department of Broadband, Communications and the Digital Economy.

Garibotti, M. C., \& Hopp, C. M. (2019). Substitution activism: The impact of \#MeToo in Argentina. In B. Fileborn \& R. Loney-Howes (Eds.), \#MeToo and the Politics of Social Change (pp. 185-199). Palgrave Macmillan. https://doi.org/10.1007/978-3030-15213-0_12

George, A., \& Harris, B. (2014). Landscapes of violence: Women surviving family violence in regional and rural Victoria. Centre for Rural and Regional Law and Justice, Deakin University.

Gill, R., \& Orgad, S. (2018). The shifting terrain of sex and power: From the 'sexualization of culture' to \#MeToo. Sexualities. 21(8), 1313-1324.

https://doi.org/10.1177/1363460718794647 
\#MeToo in regional, rural and remote Australia: An analysis of regional newspapers reports profiling the movement - Loney-Howes and Fileborn

Gilmore, W., Liang, W., \& Chikritzhs, T. (2016). The Wild West: Associations between mining and violence in Western Australia. The Australian Journal of Rural Health, 24(2), 136-143. https://doi.org/10.1111/ajr.12228

Google Trends. (2020, April). Me Too Rising. Retrieved from https://metoorising.withgoogle.com

Guggisberg, M. (2019). Aboriginal women's experiences with intimate partner sexual violence and the dangerous lives they live as a result of victimization. Journal of Aggression, Maltreatment \& Trauma, 28(2), 186-204. https://doi.org/10.1080/10926771.2018.1508106

Haire, B., Newman, C. E., \& Fileborn, B. (2019). Shitty media men. In B. Fileborn \& R. Loney-Howes (Eds.), \#MeToo and the Politics of Social Change (pp. 201-216). Palgrave Macmillan. https://doi.org/10.1007/978-3-030-15213-0_13

Hall-Sanchez, A. K. (2014). Male peer support, hunting, and separation/divorce sexual assault in rural Ohio. Critical Criminology, 22, 495-510. https://doi.org/10.1007/s10612-014-9251-6

Harkness, A., Harris, B., \& Baker, D. (2015). Locating crime in context and place: perspectives on regional, rural and remote Australia. The Federation Press.

Harrington, C. (2018). Feminist killjoys and women scorned: An analysis of news and commentary on the sexual violence allegations against Julian Assange. Feminist Criminology, 13(1), 87-111. https://doi.org/10.1177/1557085116646194

Harris, B. (2016). Violent landscapes: a spatial study of family violence. Federation Press.

Harris, B. (2018). Spacelessness, spatiality and intimate partner violence: Technologyfacilitated abuse, stalking and justice administration. In J. Maher, S. Walklate, J. McCulloch, \& K. Fitz-Gibbon. (Eds.). Intimate partner violence, risk and security: securing women's lives in a global world. Routledge.

Heberle, R. (1996). Deconstructive strategies and the movement against sexual violence. Hypatia, 11(4), 63-76. https://doi.org/10.1111/j.1527-2001.1996.tb01035.x

Hindes, S., \& Fileborn, B. (2020). "Girl power gone wrong": \#MeToo, Aziz Ansari, and media reporting of (grey area) sexual violence. Feminist Media Studies, 20(5), 639656. https://doi.org/10.1080/14680777.2019.1606843

Hindes, S., \& Fileborn, B. (2020). Reporting on sexual violence 'inside the closet': masculinity, homosexuality and \#MeToo. Crime Media Culture, online first. https://doi.org/10.1177/1741659020909872

Hooker, L., Theobald, J., Anderson, K., Billet, P., \& Baron, P. (2019). Violence against young women in non-urban areas in Australia. Trauma, Violence \& Abuse, 20(4), 534-548. https://doi.org/10.1177/1524838017725752 
Horeck, T. (2004). Public rape: Representing violation in film and fiction. Psychology Press.

Hugo, G., Tan, G., Feist, H., \& Harris, K. (2015). Population dynamics in regional Australia. Regional Australia Institute.

Ison, J. (2019). 'It's not just men and women': LGBTQIA people and \#MeToo. In B. Fileborn \& R. Loney-Howes (Eds.), \#MeToo and the Politics of Social Change (pp. 151-167). Palgrave Macmillan. https://doi.org/10.1007/978-3-030-15213-0_10

Jodie*. (2018, November 24). 16 days of activism, 2018: Survivor says \#MeToo. Bendigo Advertiser. https://www.bendigoadvertiser.com.au/story/5774309/survivor-saysmetoo-global-movement-prompts-disclosures/.

Kagal, N., Cowan, L., \& Jawad, H. (2019). Beyond the bright lights: Are minoritized women outside the spotlight able to say \#MeToo? In B. Fileborn \& R. Loney-Howes (Eds.), \#MeToo and the Politics of Social Change (pp. 133-149). Palgrave Macmillan. https://doi.org/10.1007/978-3-030-15213-0_10

Kelly, L. (1988). Surviving sexual violence. Wiley and Sons.

Kitzinger, J. (2001). Transformations of public and private knowledge: Audience reception, feminism and the experience of childhood sexual abuse. Feminist Media Studies, 1(1), 91-104. https://doi.org/10.1080/14680770120042882

Kitzinger, J. (2004). Media coverage of sexual violence against women and children. In K. Ross \& C. M. Byerly (Eds.) Women and media: international perspectives (pp. 1338.). John Wiley \& Sons. https://doi.org/10.1002/9780470776421.ch2

LGBTIQ Domestic and Family Violence Interagency \& The Centre for Social Research in Health. (2014). Calling it what it really is: a report into lesbian, gay, bisexual, transgender, gender diverse, intersex and queer experiences of domestic and family violence. CSRH, UNSW.

Loney-Howes, R. (2018). Shifting the rape script: Coming out online as a rape victim. Frontiers: A journal of women's studies, 39(2), 26-57. https://doi.org/10.5250/fronjwomestud.39.2.0026

Loney-Howes, R. (2020). Online anti-rape activism: Exploring the politics of the personal in the age of digital media. Emerald Publishing. https://doi.org/10.1108/9781838674397

Mendes, K., Ringrose, J., \& Keller, J. (2019). Digital feminist activism: Girls and women fight back against rape culture. Oxford University Press. https://doi.org/10.1093/oso/9780190697846.001.0001

Moreton-Robinson, A. (2005). Patriarchal whiteness, self determination and Indigenous women: The invisibility of structural privilege and the visibility of oppression. In B. Hocking (Ed.), Unfinished Constitutional Business: Re-thinking Indigenous SelfDetermination (pp. 61-73). Aboriginal Studies Press. 
\#MeToo in regional, rural and remote Australia: An analysis of regional newspapers reports profiling the movement - Loney-Howes and Fileborn

Morgan, J., \& Simons, M. (2018). Changing media coverage of violence against women: the role of individual cases and individual journalists. Journalism Practice, 12(9), 1165 1182. https://doi.org/10.1080/17512786.2017.1366866

Mundeen, W. (2018, June 28). So much absurd chatter. Centralian Advocate. https://www.territorystories.nt.gov.au/jspui/bitstream/10070/300853/11/Centralian\%2 0Advocate_20180626_page11_Centralian_Lifestyle_11.PDF.

O’Callaghan, T. (2018, September 11). Loddon Mallee centre against sexual assault CEO says current laws not working. Bendigo Advertiser.

https://www.bendigoadvertiser.com.au/story/5631422/call-for-reform-to-deal-withworkplace-sexual-harassment.

O'Hara, S. (2012). Monsters, playboys, virgins and whores: Rape myths in the news media's coverage of sexual violence. Language and Literature, 21(3), 247-259. https://doi.org/10.1177/0963947012444217

O’Neill, T. (2018). 'Today I speak': Exploring how victim-survivors use reddit. International Journal for Crime, Justice and Social Democracy, 7(1), 44-59. https://doi.org/10.5204/ijcjsd.v7i1.402

Palmer-Mehta, V. (2018). The subversive power of survivor rhetoric: An innovative archive of survivor discourse in New York magazine. Women's Studies in Communication, 41(2), 159-182. https://doi.org/10.1080/07491409.2018.1471764

Pease, B. (2010). Reconstructing violence rural masculinities: Responding to fractures in the rural gender order in Australia. Culture, Society \& Masculinity, 2(2), 154-164. https://doi.org/10.3149/csm.0202.154

Phipps, A. (2019). "Every woman knows a Weinstein": Political whiteness and white woundedness in \#MeToo and public feminisms around sexual violence. Feminist Formations, 31(2), 1-25. https://doi.org/10.1353/ff.2019.0014

Poulsen, J. (2017, October 21). Shame on the perpetrators. Northern Territory News. https://www.territorystories.nt.gov.au/jspui/bitstream/10070/278791/26/Northern\%20 Territory\%20News_20171021_page25_NTNews_News_25.PDF.

Powell, A., \& Henry, N. (2017). Sexual violence in a digital age. Palgrave Macmillan. https://doi.org/10.1057/978-1-137-58047-4

Powell, A. (2015). Seeking rape justice: Formal and informal responses to sexual violence through technosocial counter-publics. Theoretical Criminology, 19(4), 571-588. https://doi.org/10.1177/1362480615576271

Rae Pepin, J. (2016). Nobody's business? White male privilege in media coverage of intimate partner violence. Sociological Spectrum, 36(3), 123-141. https://doi.org/10.1080/02732173.2015.1108886 
Ragusa, A. T. (2017). Rurality's influence on women's intimate partner violence experiences and support needed for escape and healing in Australia. Journal of Social Service Research, 43(2), 270-295. https://doi.org/10.1080/01488376.2016.1248267

Rosewarne, L. (2019). \#MeToo and the reasons to be cautious. In B. Fileborn \& R. LoneyHowes (Eds.), \#MeToo and the Politics of Social Change (pp. 171-184). Palgrave Macmillan. https://doi.org/10.1007/978-3-030-15213-0_11

Ryan, T. (2019). This black body is not yours for the taking. In B. Fileborn \& R. LoneyHowes (Eds), \#MeToo and the Politics of Social Change (pp. 117-132). Palgrave Macmillan. https://doi.org/10.1007/978-3-030-15213-0_8

Ryan, H., \& Rushton, G. (October 18, 2019). The leaders of Australia's "Time's Up" movement made big promises they couldn't keep. BuzzFeed News. https://www.buzzfeed.com/hannahryan/metoo-movement-now-australia-tracey-spicer.

Salter, M. (2013). Justice and revenge in online counter-publics: Emerging responses to sexual violence in the age of social media. Crime, Media, Culture, 9(3), 225-242. https://doi.org/10.1177/1741659013493918

Saunders, S., \& Easteal, P. (2012). “Fit in or f\#\$@ off!”: the (non) disclosure of sexual harassment in rural workplaces. International Journal of Rural Law and Policy, 2 (Papers and abstracts from the Second National Rural and Regional Law and Justice Conference 2012), 1-17. https://doi.org/10.5130/ijrlp.i2.2012.3127

Senior, K., Helmer, J., \& Chenhall, R. (2017). 'As long as he's coming home to me': vulnerability, jealousy and violence in young people's relationships in remote, rural and regional Australia. Health Sociology Review, 26(2), 204-218. https://doi.org/10.1080/14461242.2016.1157697

Serisier, T. (2018). Speaking out: Feminism, rape and narrative politics. Springer. https://doi.org/10.1007/978-3-319-98669-2

Smith, A. L., Bond, C. E. W., \& Jeffries, S. (2019). Media discourses of intimate partner violence in Queensland newspapers. Journal of Sociology, 55(3), 571-586. https://doi.org/10.1177/1440783319837612

Sutherland, G., Easteal, P., Holland, K., \& Vaughan, C. (2019). Mediated representations of violence against women in the mainstream news in Australia. BMC Public Health, 19(1), 502-510. https://doi.org/10.1186/s12889-019-6793-2

Sutherland, G., McCormack, A., Pirkis, J., Easteal, P., Holland, K., \& Vaughan, C. (2015). Media representations of violence against women and their children: state of knowledge paper. ANROWS.

Sutherland, G., Simons, M., \& Blatchford, A. (2017). News media and the primary prevention of violence against women and their children: emerging evidence, insights and lessons. Report prepared for Our Watch. University of Melbourne. 
\#MeToo in regional, rural and remote Australia: An analysis of regional newspapers reports profiling the movement - Loney-Howes and Fileborn

Tuffield, R. (2017, October 19). Women need to be respected. Shepparton News. https://www.pressreader.com/australia/sheppartonnews/20171019/281767039458546.

Victoria Police. (2020). Sexual offences and child abuse investigation teams: Multidisciplinary centres. https://www.police.vic.gov.au/sexual-offences-and-child-abuseinvestigation-teams\#multidisciplinary-centres.

Vinson, T. (2007). Dropping off the edge: Mapping the distribution of disadvantage in Australia. Report commissioned by Jesuit Social Services and Catholic Social Services Australia, Jesuit Social Services Melbourne.

Waterhouse-Watson, D. (2016). News media on trial: Towards a feminist ethics of reporting footballer sexual assault trials. Feminist Media Studies, 16(6), 952-967. https://doi.org/10.1080/14680777.2016.1162827

Wear, A. (2012). Collaborative approaches to regional governance-lessons from Victoria. Australian Journal of Public Administration, 71(4), 469-474. https://doi.org/10.1111/1467-8500.12002

Wendt, S., Chung, D., Elder, A., Hendrick, A., \& Hartwig, A. (2017). Seeking help for domestic and family violence: exploring regional, rural and remote women's coping experiences. Final report. ANROWS Horizons, 06/2017. ANROWS.

Wendt, S. (2016). Intimate violence and abuse in Australian rural contexts. In J. Donnermeyer (Ed.), The Routledge International Handbook of Rural Criminology (pp. 191-199). Routledge. https://doi.org/10.4324/9781315755885-22

Wheeler, F., \& Laing, J. (2008). Tourism as a vehicle for liveable communities: Case studies from regional Victoria, Australia. Annals of Leisure Research, 11(1-2), 242-263. https://doi.org/10.1080/11745398.2008.9686795

Wright, K., Swain, S., \& McPhillips, K. (2017). The Australian royal commission into institutional responses to child sexual abuse. Child Abuse \& Neglect, 74, 1-9. https://doi.org/10.1016/j.chiabu.2017.09.031

Zeng, J. (2019). You say \#MeToo, I say \#MiTu: China's online campaigns against sexual abuse. In B. Fileborn \& R. Loney-Howes (Eds.), \#MeToo and the Politics of Social Change (pp. 71-83). Palgrave Macmillan. https://doi.org/10.1007/978-3-030-15213$0 \_5$ 
International Journal of Rural Criminology, Volume 5, Issue 2 (September), 2020

\section{Appendix A: Final sample of articles used in analysis}

\begin{tabular}{|c|c|c|c|c|}
\hline $\begin{array}{l}\text { Location (State and } \\
\text { town/city) }\end{array}$ & Newspaper & Title of article & $\begin{array}{l}\text { Date } \\
\text { published }\end{array}$ & Author (where listed) \\
\hline \multicolumn{5}{|l|}{ New South Wales } \\
\hline Grafton & Daily Examiner & Forget the token day, talk the talk & $21 / 11 / 2018$ & Lesley Apps (op-ed) \\
\hline Grafton & Daily Examiner & Land of hope and despair & $18 / 12 / 2018$ & Lesley Apps (op-ed) \\
\hline Grafton & Daily Examiner & No.10 & $8 / 12 / 2018$ & Nav Navratil \\
\hline Wollongong & Illawarra Mercury & Figtree HS' crucial role in the first Australian Women's Day & $22 / 09 / 2018$ & Agron Latifi \\
\hline Newcastle & Newcastle Herald & $\begin{array}{l}\text { The founder of Got Your Back Sista is on a mission to empower } \\
\text { women }\end{array}$ & $2 / 11 / 2019$ & Jade Lazarevic \\
\hline Newcastle & Newcastle Herald & One year on: Respect. Now. Always & $2 / 08 / 2018$ & Professor Liz Burd \\
\hline Newcastle & Newcastle Herald & Australian women and equality: the way forward & $24 / 05 / 2018$ & Robyn Considine \\
\hline Newcastle & Newcastle Herald & Same rage after Harvey and Eurydice & $26 / 10 / 2018$ & Author unknown \\
\hline Newcastle & Newcastle Herald & $\begin{array}{l}\text { Hunter women at Reclaim the Night march demand right to live free } \\
\text { form fear and violence }\end{array}$ & $27 / 10 / 2018$ & Helen Gregory \\
\hline Newcastle & Newcastle Herald & Maq lets her emotions run free & $3 / 03 / 2018$ & Author unknown \\
\hline Wagga Wagga & $\begin{array}{l}\text { Wagga Daily } \\
\text { Advertiser }\end{array}$ & Wagga academic labels attitudes to domestic violence 'depressing' & $5 / 12 / 2018$ & Annie Lewis \\
\hline Wagga Wagga & $\begin{array}{l}\text { Wagga Daily } \\
\text { Advertiser }\end{array}$ & $\begin{array}{l}\text { Rise of the 'unwanted kiss': Wagga businesswomen speaks on } \\
\text { boundaries }\end{array}$ & $7 / 09 / 2019$ & Jessica McLaughlin \\
\hline Wagga Wagga & $\begin{array}{l}\text { Wagga Daily } \\
\text { Advertiser }\end{array}$ & \#MeToo is more than a social media trend & $18 / 01 / 2018$ & Opinion piece \\
\hline \multicolumn{5}{|l|}{ Northern Territory } \\
\hline Alice Springs & Centralian Advocate & Empowering our women & $3 / 08 / 2018$ & Leah Brahman \\
\hline Alice Springs & Centralian Advocate & Worthy of so much more & $2 / 03 / 2018$ & Dianna Newham \\
\hline Alice Springs & Centralian Advocate & So much absurd chatter & $26 / 06 / 2018$ & Warren Mudine (op-ed) \\
\hline Darwin & $\begin{array}{l}\text { Northern Territory } \\
\text { News }\end{array}$ & Survivors forced to relive the nightmare & $14 / 07 / 2018$ & Jason Walls \\
\hline Darwin & $\begin{array}{l}\text { Northern Territory } \\
\text { News }\end{array}$ & Shame on the perpetrators & $21 / 10 / 2017$ & Jill Poulsen \\
\hline Darwin & $\begin{array}{l}\text { Northern Territory } \\
\text { News }\end{array}$ & Campaign to change NT laws gets US celebrity boost & $10 / 11 / 2018$ & Nina Funnel \\
\hline
\end{tabular}




\begin{tabular}{|c|c|c|c|c|}
\hline \multicolumn{5}{|l|}{ Queensland } \\
\hline Fraser Coast & $\begin{array}{l}\text { Fraser Coast } \\
\text { Chronical }\end{array}$ & Shame and fear silence victims & $10 / 05 / 2018$ & Sherele Moody \\
\hline Bundaberg & NewsMail & Sharp message for men & $17 / 01 / 2019$ & Sarah Steger \\
\hline Sunshine Coast & Sunshine Coast Daily & Ugly truth: rape is not a beauty pageant & $12 / 10 / 2019$ & Sherele Moody \\
\hline Sunshine Coast & Sunshine Coast Daily & More Coast men seek support to heal from sexual violence & $5 / 05 / 2018$ & Sherele Moody \\
\hline Sunshine Coast & Sunshine Coast Daily & It's about more than money & $21 / 10 / 2017$ & Author unknown \\
\hline Toowoomba & $\begin{array}{l}\text { The Toowoomba } \\
\text { Chronicle }\end{array}$ & New digital billboard in heart of the city & $16 / 01 / 2018$ & Author unknown \\
\hline Gympie & The Gympie Times & More Gympie blokes seek help to heal from sexual violence & $3 / 05 / 2018$ & Sherele Moody \\
\hline Townsville & Townsville Bulletin & Too terrified to tell police & $4 / 05 / 2018$ & Sherele Moody \\
\hline Townsville & Townsville Bulletin & Townsville Bulletin Uni vows to call out sex crime & $20 / 11 / 2018$ & Author unknown \\
\hline Townsville & Townsville Bulletin & Toxic attitude is an injustice to masculinity & $22 / 01 / 2019$ & $\begin{array}{l}\text { Stefan Aeberhard (opinion } \\
\text { piece) }\end{array}$ \\
\hline Townsville & Townsville Bulletin & Finally reprieve from witch hunt & $13 / 01 / 2018$ & $\begin{array}{l}\text { William Ross (opinion } \\
\text { piece) }\end{array}$ \\
\hline \multicolumn{5}{|l|}{ Tasmania } \\
\hline Bernie & Bernie Advocate & Power to sexual crime victims & $21 / 10 / 2019$ & Adam Holmes \\
\hline Bernie & Bernie Advocate & Harassment and shared online & $20 / 11 / 2017$ & Imogen Elliott \\
\hline Bernie & Bernie Advocate & Rise in sexual assault victims, report states & $26 / 01 / 2018$ & Matt Maloney \\
\hline Launceston & Launceston Examiner & National approach needed on sexual assault & $26 / 01 / 2018$ & Author unknown \\
\hline Launceston & Launceston Examiner & change to $194 \mathrm{~K}$ Welcomed & $21 / 10 / 2019$ & Adam Holmes \\
\hline Launceston & Launceston Examiner & Rise in sexual assault victims, report says & $26 / 01 / 2018$ & Matt Maloney \\
\hline Launceston & Launceston Examiner & Tim Winton to host workshop on "toxic masculinity" in Launceston & $23 / 03 / 2018$ & Caitlin Jarvis \\
\hline Launceston & Launceston Examiner & Modern-day feminism at Zonta & $14 / 04 / 2018$ & Caitlin Jarvis \\
\hline \multicolumn{5}{|l|}{ Victoria } \\
\hline Ballarat & Ballarat Courier & New organisation combats sexual harassment in the workplace & $4 / 02 / 2019$ & Rochelle Kirkham \\
\hline Ballarat & Ballarat Courier & Online campaign shows magnitude of sexual violence in Ballarat & $21 / 10 / 2017$ & Victoria Stone-Meadows \\
\hline Ballarat & Ballarat Courier & Debate over Picasso's moral view & $24 / 02 / 2019$ & Caleb Cluff \\
\hline Ballarat & Ballarat Courier & Dissecting respectful relationships on stage & $7 / 07 / 2018$ & Ashleigh McMillan \\
\hline Ballarat & Ballarat Courier & Family violence survivor Stacey Speaks to shine light on dark shadows & $29 / 08 / 2018$ & Melanie Whelan \\
\hline Ballarat & Ballarat Courier & The women helping to push for parity in Ballarat & $7 / 03 / 2018$ & Melanie Whelan \\
\hline
\end{tabular}


International Journal of Rural Criminology, Volume 5, Issue 2 (September), 2020

\begin{tabular}{|c|c|c|c|c|}
\hline Ballarat & Ballarat Courier & Police and rainbow organisers meet before festival kicks off & $22 / 01 / 2018$ & Author unknown \\
\hline Bendigo & Bendigo Advertiser & Share stories of \#MeToo in central Victoria & $7 / 12 / 2019$ & Tara Cosoleto \\
\hline Bendigo & Bendigo Advertiser & Experts urge courage & $25 / 11 / 2019$ & Emma D'Agostino \\
\hline Bendigo & Bendigo Advertiser & $\begin{array}{l}\text { 'Call it out': Violence prevention experts urge action on gender } \\
\text { equality }\end{array}$ & $25 / 11 / 2019$ & Emma D'Agostino \\
\hline Bendigo & Bendigo Advertiser & Survivor says \#MeToo: global movement prompts disclosures & $24 / 11 / 2018$ & "Jodie" \\
\hline Bendigo & Bendigo Advertiser & Call for reform to deal with workplace sexual harassment & $12 / 09 / 2018$ & Tom O'Callaghan \\
\hline Bendigo & Bendigo Advertiser & Meet the workers bringing hope to sexual assault survivors & $8 / 12 / 2018$ & Emma D'Agostino \\
\hline Bendigo & Bendigo Advertiser & \#MeToo at the heart of Talking Justice discussions in Bendigo & $21 / 04 / 2018$ & Adam Holmes \\
\hline Bendigo & Bendigo Advertiser & Hear, believe, support: act to eliminate gender-based violence & $24 / 11 / 2018$ & Emma D'Agostino \\
\hline Bendigo & Bendigo Advertiser & Serious obstacles between women and justice & $18 / 05 / 2018$ & \\
\hline Bendigo & Bendigo Advertiser & To reach our full potential & $25 / 11 / 2018$ & $\begin{array}{l}\text { Julie Oberin (CEO Annie } \\
\text { North Inc) }\end{array}$ \\
\hline Bendigo & Bendigo Advertiser & More disclosures possibly behind sex offence rise in Bendigo & $25 / 09 / 2018$ & Natalie Croxon \\
\hline Bendigo & Bendigo Advertiser & Confronting child sexual abuse through theatre & $3 / 04 / 2019$ & Emma D'Agostino \\
\hline Bendigo & Bendigo Advertiser & Black gowns at the Golden Globes a power statement, says Chief & $6 / 01 / 2018$ & Natalie Croxon \\
\hline Geelong & Geelong Advertiser & Addy readers have their say - letters and texts & $21 / 02 / 2018$ & Members of the public \\
\hline Geelong & Geelong Advertiser & Find a balance & $23 / 02 / 2018$ & Peter Moore (op-ed) \\
\hline Geelong & Geelong Advertiser & \#MeToo failure & $16 / 11 / 2018$ & Peter Moore (op-ed) \\
\hline Geelong & Geelong Advertiser & Workers taking a stand & $29 / 01 / 2019$ & Olivia Shying \\
\hline Geelong & Geelong Advertiser & Name and shame a dangerous game & $17 / 02 / 2018$ & Karen Matthews (op-ed) \\
\hline Geelong & Geelong Advertiser & My say on Saturday & $5 / 10 / 2019$ & Karen Matthews (op-ed) \\
\hline Geelong & Geelong Advertiser & Deakin expert: Hollywood sex saga will change our workplaces & $7 / 11 / 2017$ & Jaimee Wilkens \\
\hline Geelong & Geelong Advertiser & Turning trauma around & $29 / 01 / 2019$ & Editorial (author unnamed) \\
\hline Geelong & Geelong Advertiser & A show of respect & $20 / 03 / 2018$ & Chris Mackey \\
\hline Shepparton & Shepparton News & Womenneedtoberespected & $19 / 10 / 2017$ & Rhiannon Tuffield \\
\hline Warrnambool & $\begin{array}{l}\text { The Warnambool } \\
\text { Standard }\end{array}$ & MeToo gives women strength in numbers against sexual harassment & $14 / 10 / 2017$ & Clare Quirk \\
\hline Warrnambool & $\begin{array}{l}\text { The Warnambool } \\
\text { Standard }\end{array}$ & Women to unite in song for Winter Weekends concert & $24 / 05 / 2018$ & Madeline McNeil \\
\hline
\end{tabular}

